\title{
Differential Effects of Portal Diversion on Hepatocyte Function (HF) and Hepatic Reticuloendothelial Cell (HRES) Activity in the Dog
}

\author{
L. P. Edgcomb, M.D., J. A. Knol, M.D., W. E. Strodel, M.D., \\ AND F. E. ECKHAUSER, M.D. \\ Department of Surgery, University of Michigan, and Veterans \\ Administration Medical Center, Ann Arbor, Michıgan 48109
}

Presented at the Annual Meeting of the Association for Academic Surgery, Chicago, Illinois, November 9-11, 1981

\begin{abstract}
End-to-side portocaval shunts (PCS) were constructed in six dogs to evaluate the effect of complete portal blood flow diversion on hepatocellular structure and function, hepatic reticuloendothelial (RE) activity, and serum opsonıc actıvity (OA). RE activity remained normal after PCS despite a $40 \%$ reduction in estimated hepatic blood flow. Tissue distribution of injected colloid shifted away from liver to spleen, lung, and bone marrow. OA decreased to $40 \%$ of baseline values 6 weeks after PCS and remained low. Postshunt changes in hepatic morphology primarily affected hepatocytes and included deglycogenation and loss of rough endoplasmic reticulum. Significant changes in Kupffer cell morphology were not observed. Complete portal flow diversion in the dog caused profound alterations in hepatocellular structure and function without compromising Kupffer cell phagocytic and metabolic activity. Kupffer cells may be less dependent than hepatocytes upon hepatotrophic factors contained in portal blood. OA did not correlate with changes in vascular lipid clearance, suggesting that either phagocytosis of RES test lipid in the dog is not dependent on prior opsonization, or that the assay used was neither sensitive nor specific enough to measure a critical opsonic threshold required for effective phagocytosis.
\end{abstract}

\section{INTRODUCTION}

The vascular clearance of particulate matter, endotoxin, and other antigenic materials is a physiological function of the fixed macrophages of the reticuloendothelial (RE) system [25]. Macrophages localized to the sinuoids of the liver (Kupffer cells, KC) and spleen account for nearly $90 \%$ of intravascular phagocytosis [5], and experimental data suggest that the serum factors or "opsonins" are important regulators of RE phagocytic activity [21, 23, 27].

Functional alterations of the RE system have been demonstrated in many pathological conditions including cirrhosis of the liver [32]. Experimental systemic diversion of portal blood containing hepatotrophic factors has been shown to profoundly affect hepatocellular structure and function [30]. Most important evidence of compromised $\mathrm{KC}$ function in cirrhosis has been derived indirectly from observations regarding the reduced intravascular clearance of intravenously injected radiolabeled colloids $[4,10]$. It is not known whether a primary functional defect or a reduction in effective sinusoidal perfusion causes these abnormalities in phagocytic and metabolic activity.

The purposes of this study were to measure the effects of end-to-side portocaval shunt on canine $\mathrm{KC}$ and hepatocellular structure and function and to relate these changes temporally to alterations in serum opsonic activity.

\section{MATERIALS AND METHODS}

Twelve conditioned mongrel dogs, 10 to $30 \mathrm{~kg}$ in body weight, were maintained on standard kennel chow and water ad libitum. Each animal underwent baseline determinations of hepatic reticuloendothelial phagocytic index(PI) and degradative (DI) index, as well as opsonic activity (OA), and estimated hepatic blood flow (EHBF). Liver function was assessed by determining serum 
levels of: glutamic oxaloacetic transaminase (SGOT), glutamic pyruvic transaminase (SGPT), total protein (TP), albumin (ALB), globulin (GLOB), as well as serum protein electrophoresis (SPEP).

The RE phagocytic index was determined using a gelatinized RES test lipid emulsion consisting of anhydrous triolein mixed with glycerol and alcohol soluble soy lecithin in a ratio of $10: 10: 1$ by weight, respectively [11]. To this trace amounts of ${ }^{131}$ I-labeled triolein were added. Immediately prior to use, the anhydrous base was mixed with a $0.3 \%$ gelatin- $5 \%$ dextrose in water solution using a Waring blender at high speed for 10 min resulting in $10 \%$ emulsion with an average particle size diameter of 1-7 $\mu \mathrm{m}$. Each animal received an intravenous dose of 150 $\mathrm{mg} / \mathrm{kg}$ of anhydrous base equivalent emulsion containing 30 to $50 \mu \mathrm{Ci}$ of ${ }^{131} \mathrm{I}$. Ten drops of Lugol's solution were administered to all test animals one day prior to and on the morning of the study.

Anesthesia was induced with $20 \mathrm{mg} / \mathrm{kg}$ of thiamylol sodium (Suritol) to permit placement of a central venous catheter by way of the external jugular vein, a peripheral catheter into an upper extremity vein, and a catheter into the urinary bladder. Animals were then awakened and maintained in a simple restraining harness throughout the study period. Throughout the 2 -hr test period, $2 \mathrm{ml} / \mathrm{kg} / \mathrm{min}$ of $0.9 \%$ normal saline was administered intravenously to each animal.

The test lipid emulsion was administered intravenously over $60 \mathrm{sec}$. Four milliliters of central venous blood was withdrawn every minute for $10 \mathrm{~min}$, then every $15 \mathrm{~min}$ for a total of $2 \mathrm{hr}$. One milliliter was saved for subsequent assay of ${ }^{131} I$ activity. The remaining $3 \mathrm{ml}$ sample of blood was centrifuged at $1400 \mathrm{~g}$ for 10 additional min at $4^{\circ} \mathrm{C}$, and a $1-\mathrm{ml}$ aliquot of serum was removed. Each sample was precipitated twice with 1 $\mathrm{ml}$ of $30 \%$ tricholoroacetic acid, and centrifuged at $1400 \mathrm{~g}$ for 10 additional $\mathrm{min}$ at $4^{\circ} \mathrm{C}$. One milliliter of resulting protein and lipid devoid supernatant was saved for assay of free serum ${ }^{131} I$.
Urinary output was collected at 15-min intervals and recorded. One-milliliter aliquots of urine were withdrawn from each 15 min collection for measurement of urine ${ }^{131} I$.

Whole blood ${ }^{131}$ I activity was plotted versus time on semilog scale and clearance of lipid was treated as linear for the first 10 min following infusion [11, 12]. Using the least-squares method of linear regression analysis, an equation was derived, and the half-time $\left(T_{1 / 2}\right)$ of lipid clearance and the resulting $K$ constant were calculated. The $K$ constant, obtained by dividing $0.693(\ln 2)$ by the $T_{1 / 2}(\mathrm{~min})$, represented the phagocytic index (PI).

Degradation or deiodination of phagocytized ${ }^{131}$ I-labeled lipid results from RE metabolic activity. Levels of free ${ }^{131}$ I activity were evaluated by measuring radioactivity in the supernatant of previously precipitated whole blood samples and in 15-min urine samples. Cumulative ${ }^{131}$ I clearance, representative of overall lipid metabolism, was determined by summing activity levels from interval urine samples. Cumulative ${ }^{131} \mathrm{I}$ activity was plotted versus time on a semilog scale; $T_{1 / 2}$ was the time required to excrete half the total cumulative ${ }^{131} \mathrm{I}$ activity. The resulting $K$ constant was the degradative index (DI). Whole blood, supernatant, and urine ${ }^{131}$ I activity plotted together gives a profile of lipid clearance and metabolism (Fig. 1).

Opsonic activity was detected by determining the ability of serum samples to cause agglutination of gelatin-coated carboxy-latex particles in the presence of heparin [9]. Carboxy-latex particles $0.892 \mu \mathrm{m}$ in diameter were covalently bonded to gelatin using the carboidimide reaction, diluted in Hank's balanced salt solution (HBSS) to a particle concentration of $1 \times 10^{8} / \mathrm{ml}$ and refrigerated at $10^{\circ} \mathrm{C}$ for use in the assay. One to three milliliters clotted of dog blood was centrifuged at $1000 \mathrm{~g}$ for $10 \mathrm{~min}$. Fifty milliliters each of serum, particle solution, and HBSS to which 20 units heparin/ml had been added comprised the test mixture. Control tubes contained similar constituents without 
heparin. After $1 \mathrm{hr}$ of agitation at $37^{\circ} \mathrm{C}$, the reaction was stopped by addition of $3 \mathrm{ml}$ of phosphate-buffered saline (PBS) and sedimented over night at $4^{\circ} \mathrm{C}$. All assays were performed in triplicate. The optical density (OD) of the resulting supernatant was measured against a PBS blank at $650 \mathrm{~nm}$ in a light spectrophotometer and the opsonic activity (OI) was calculated using

$$
\frac{(1-\text { average test OD) }}{(\text { average control OD) }} \times 100 \% \text {. }
$$

Activity indices were normalized to control values and plotted as mean percentage activity versus time.

Estimated hepatic blood flow (EHBF) was determined scintigraphically by measuring the rate of hepatic uptake of a "subcritical" dose of $500 \mu \mathrm{Ci}$ of ${ }^{99 m} \mathrm{Tc}$-sulfur colloid. A 2.5-cm-diameter $\mathrm{NaI} \gamma$ probe was positioned over the liver with constant geometry maintained throughout the experiment. After rapid intravenous injection of the radiolabeled sulfur colloid, 1-sec instantaneous count rates were recorded for $10 \mathrm{~min}$. Least-squares linear regression analysis of data collected during the first 2 min of count rate collection was representative of hepatic blood flow at low particle doses. Linear regression analysis was used to determine the $T_{1 / 2}(\mathrm{~min})$ and $K\left(\mathrm{~min}^{-1}\right)$. Estimated hepatic sinusoidal blood flow was calculated from

$$
\mathrm{EHBF}=K\left(\mathrm{~min}^{-1}\right)
$$

$$
\times \text { body weight }(\mathrm{kg}) \times 0.095 \text {, }
$$

where 0.095 represents the percentage blood volume to body weight in the dog.

Six animals underwent construction of end-to-side portocaval shunts (PCS) and six others underwent sham operations (control). All dogs were anesthetized with nitrous oxide and $0.5 \%$ fluothane. Streptomycin (0.5 g) and penicillin (250,000 units) were administered once daily for 5 days following operation. Animals were studied preoperatively and at 3,6, and 9 weeks postoperatively. During the last study period, each animal received $1 \mathrm{mCi}$ of TSC intravenously over $5 \mathrm{~min}$.

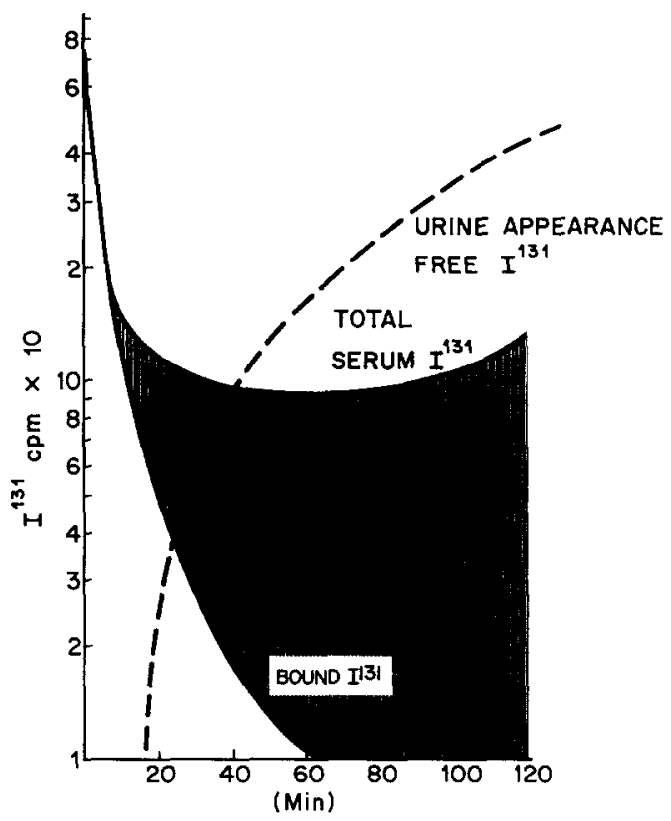

FIG. 1. Demonstrates the phagocytic and degradative profiles of intravenously injected ${ }^{131}$ I RES test lipid emulsion.

Ten minutes later an open liver biopsy was obtained. Specimens were immediately fixed in $10 \%$ buffered formalin and $2 \%$ gluteraldehyde for light and electron microscopy, respectively. Exasanguinated liver, spleen, and lung weights were obtained following sacrifice and a specimen of bone marrow was obtained from the proximal femur. Each organ was assayed for radioactivity per gram of tissue weight. Tissue distribution was expressed as the percentage injected dose phagocytized per gram tissue of each organ (\% ID/g) and per total organ (\% ID/TO). Bone marrow was assumed to represent $2 \%$ body weight. All data, represented as $\bar{x}$ $\pm \mathrm{SD}$, were analyzed using Student's $t$ and unpaired $t$ tests.

\section{RESULTS}

There was no statistically significant change in either $t$ value of lipid emulsion clearance or phagocytic index (PI) at 3,6 , or 9 weeks postshunt compared to preoperative values. In addition, there was no sig- 
TABLE 1

Effects of Portocaval Shunt on Vascular Clearance and Degradation of Intravenously INJECTED ${ }^{131}$ I TEST LIPID EMULSION

\begin{tabular}{ccccc}
\hline & & \multicolumn{3}{c}{ Postshunt } \\
\cline { 3 - 5 } & Preshunt & 3 weeks & 6 weeks & 9 weeks \\
\hline Half-time lipid & & & & \\
clearance (min) & $6.47 \pm 1.32$ & $6.00 \pm 0.39$ & $5.89 \pm 0.38$ & $6.23 \pm 0.86$ \\
$\begin{array}{c}\text { Phagocytic index } \\
\text { Half-time urine }\end{array}$ & 0.107 & 0.116 & 0.117 & 0.111 \\
appearance $(\min )$ & $86.5 \pm 7.6$ & $84.2 \pm 4.6$ & $79.3 \pm 6.5$ & $83.0 \pm 8.5$ \\
Degradative index & 0.008 & 0.008 & 0.009 & 0.008 \\
\hline
\end{tabular}

$a \ln 2 / T_{1 / 2}$

nificant difference in the $t$ of urine ${ }^{131} I$ activity or the degradative index (DI) at these test periods compared to preoperative values (Table 1).

Estimated hepatic sinusoidal blood flow (EHBF) decreased significantly $(P<0.01)$ after portocaval shunting from $49.1 \pm 3.5$ to $26.9 \pm 2.7 \mathrm{ml} / \mathrm{min} / \mathrm{kg}$ body weight. Attempts to autoregulate or restore EHBF toward preshunt values were not observed at 6 or 9 weeks following operation in any test animal.

Elevations in serum transaminase values were observed in all PCS animals (Fig. 2) with wide variations at each time interval.

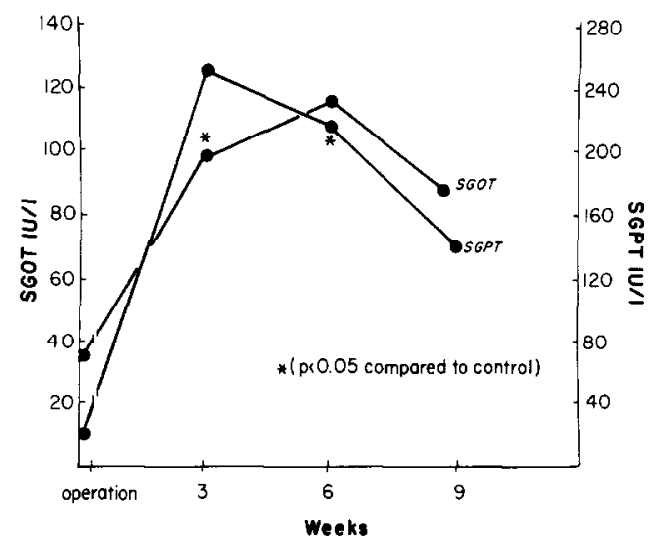

FIG. 2. Illustrates the sequential changes in SGOT and SGPT values following portocaval shunt compared to controls. SGOT and SGPT values were significantly $(P<0.05)$ increased at 3 and 6 weeks, respectively.
(SGOT) was significantly $(P<0.05)$ elevated at 3 weeks, returned to control values by 9 weeks. Similarly, SGPT was significantly $(P<0.05)$ elevated at 6 weeks but tended to return toward normal by 9 weeks.

Levels of serum protein and albumin slowly declined throughout the course of the study. Albumin levels were significantly depressed below control values at 6 weeks and remained low. Total protein levels decreased more slowly achieving significance $(P$ $<0.05) 9$ weeks postshunt. No demonstrable trends were observed among electrophoretically detemined protein fractions (Fig. 3).

Normalized opsonic activity declined pro-

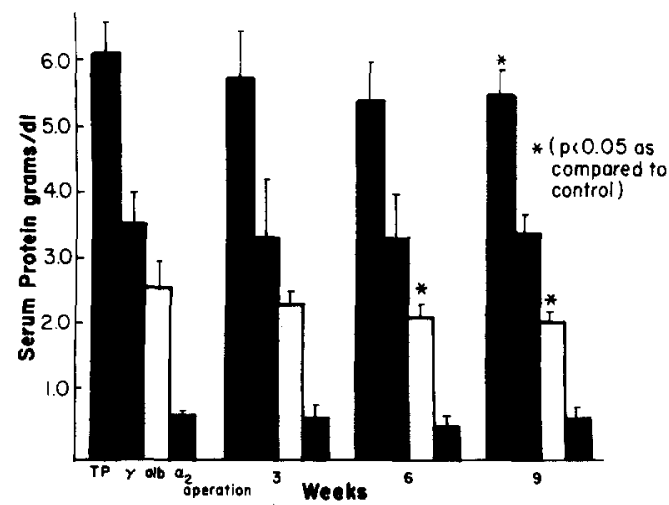

Fig. 3. Illustrates the electrophoretic profile of serum proteins before and up to 9 weeks after portocaval shunt. Total protein and albumin were decreased significantly $(P<0.05)$ by 9 weeks without a demonstrable decrease in $\gamma$ or $\alpha-2$ globulin fractions. 
gressively following PCS. By Week 6, OA decreased significantly $(P<0.01)$ to less than $40 \%$ of preoperative levels. Depressed OA persisted through the ninth week (Fig. 4).

Tissue distribution of intravenously injected TSC changed dramatically after PCS. The percentage injected dose phagocytized per total organ (\% ID/TO) shifted from the liver to the spleen, lung, and bone marrow. There appeared to be a significant postshunt increase in phagocytized particles $(\% \mathrm{ID} / \mathrm{g})$ in both the liver and spleen compared to controls (Table 2). Observed changes in tissue distribution of radioactivity did not correlate with the vascular clearance $\left(T_{1 / 2}\right.$ or $\left.\mathrm{PI}\right)$ of injected test lipid emulsion.

Among control animals liver tissue appeared relatively normal with hepatocytes arranged in plates of one cell thickness separated by sinusoids that were occasionally dilated adjacent to terminal hepatic venules. The majority of hepatic parenchymal cells contained a single central nucleus with a prominent nucleolus, were plump, and contained abundant glycogen. Kupffer cells were not prominent (Fig. 5a). Transmission electron micrographs of livers from control animals showed hepatocytes with a normal complement of glycogen, normal rough and smooth endoplasmic reticulum, normal mitochondria, and scant cytoplasmic lysosomes. Spaces of Disse contained occasional collagen bundles. Fat and endothelial cells unremarkable. Kupffer cells contained occasional vacuoles filled with debris (Fig. 5b).

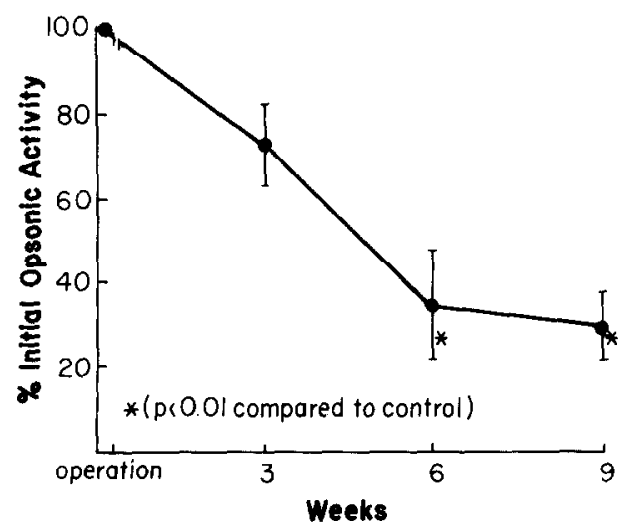

FIG. 4. Changes in serum opsonic activity normalized to control values. Following portocaval shunt, OA decreased significantly $(P<0.01)$ over the initial 6-week postshunt interval and then stabilized.

Acute diversion of portal flow resulted in demonstrable morphologic liver changes. Hepatocytes developed an eosinophilic finely granular cytoplasm and exhibited marked reduction in overall size and glycogen content. Dilatation of sinusoids became more marked. Hepatocyte nuclei sizes appeared more variable and many cells contained two or more nuclei. Nucleoli were more abundant. Kupffer cells were prominent and appeared filled with refractile amphophyllic material (Fig. 6a). Transmission electron microscopy demonstrated marked depletion of cellular glycogen. Mitochondria were abundant and slightly more variable in size. Their appearance may have been due to decreased cell volume. Rough endoplasmic reticulum appeared less prominent with some

TABLE 2

Effect of Portocaval Shunt on Vascular Clearance and Tissue Distribution OF INTRAVENOUSLY INJECTED ${ }^{99 m}$ TC

\begin{tabular}{|c|c|c|c|c|c|c|c|c|}
\hline \multirow{2}{*}{$\begin{array}{l}\text { Experimental } \\
\text { groups }\end{array}$} & \multirow{2}{*}{$\begin{array}{l}\text { Half-time } \\
\text { clearance }\end{array}$} & \multirow{2}{*}{$\begin{array}{c}\text { Phagocytic } \\
\text { index }\end{array}$} & \multicolumn{2}{|c|}{ Liver } & \multicolumn{2}{|c|}{ Lungs" } & \multicolumn{2}{|c|}{ Spleen" } \\
\hline & & & $\%$ ID $/ \mathrm{g}$ & $\%$ ID/TO & $\%$ ID $/ g$ & $\% \mathrm{ID} / \mathrm{TO}$ & $\%$ ID $/ 8$ & $\%$ ID $/ \mathrm{TO}$ \\
\hline Control & $6.2 \pm 1.32$ & 0.046 & $0.14 \pm 0.03$ & $82.7 \pm 6.3$ & $0.07 \pm 0.07$ & $2.3 \pm 1.3$ & $0.05 \pm 0.02$ & $6.7 \pm 2.7$ \\
\hline PCS & $6.23+0.86$ & 0.048 & $0.23 \pm 0.08^{*}$ & $53.4 \pm 16$ & $0.01 \pm 0.01$ & $9.7 \pm 8.0^{*}$ & $0.55 \pm 0.23$ & $26.8 \pm 12.0^{*}$ \\
\hline
\end{tabular}

\footnotetext{
- Tissue distribution data (mean \pm standard error) determined at 15 min postinjection and expressed as percentage injected dose phagocytized per gram (ID/g) and per total organ (ID/TO).

$* P<0.05$
} 


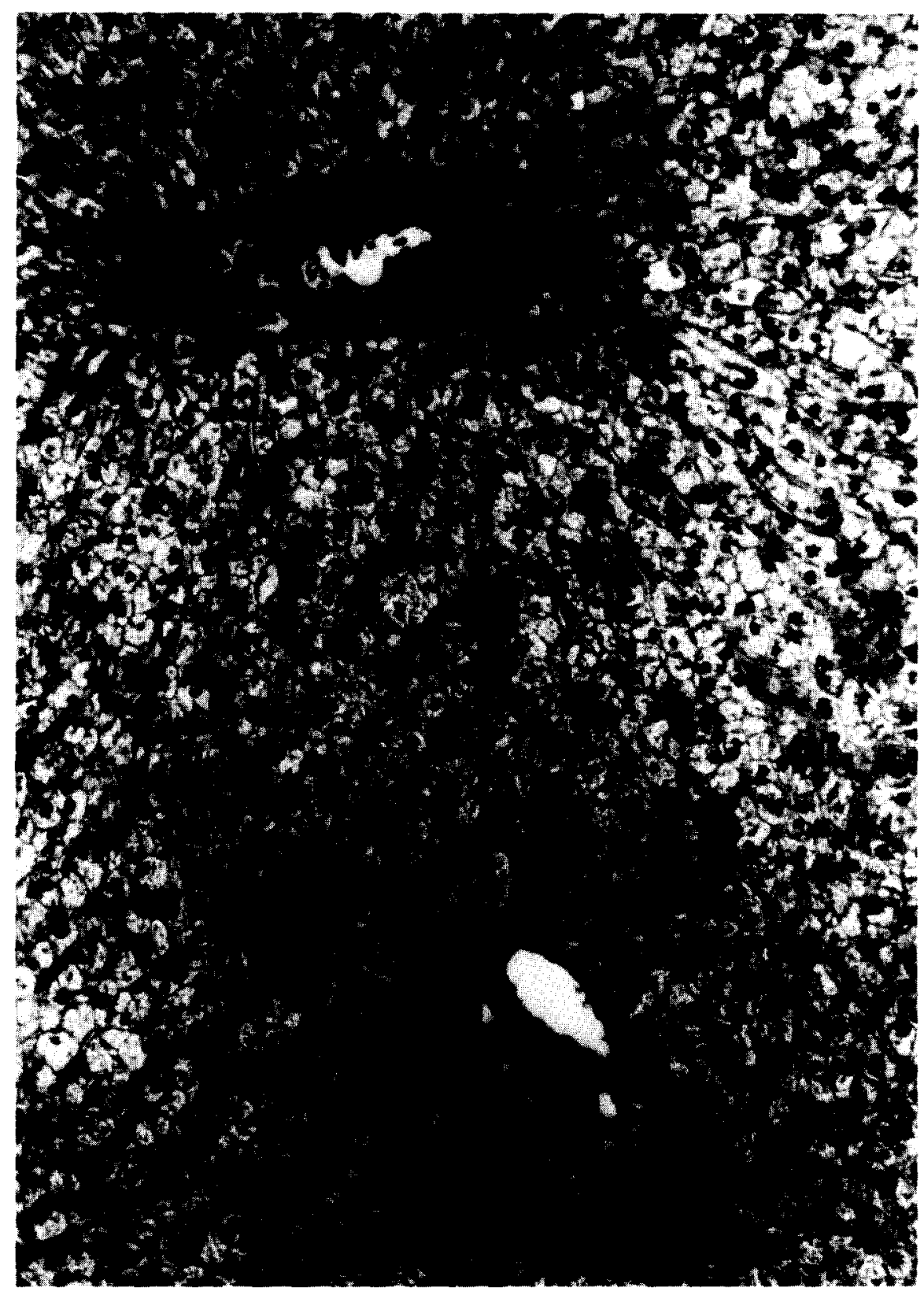




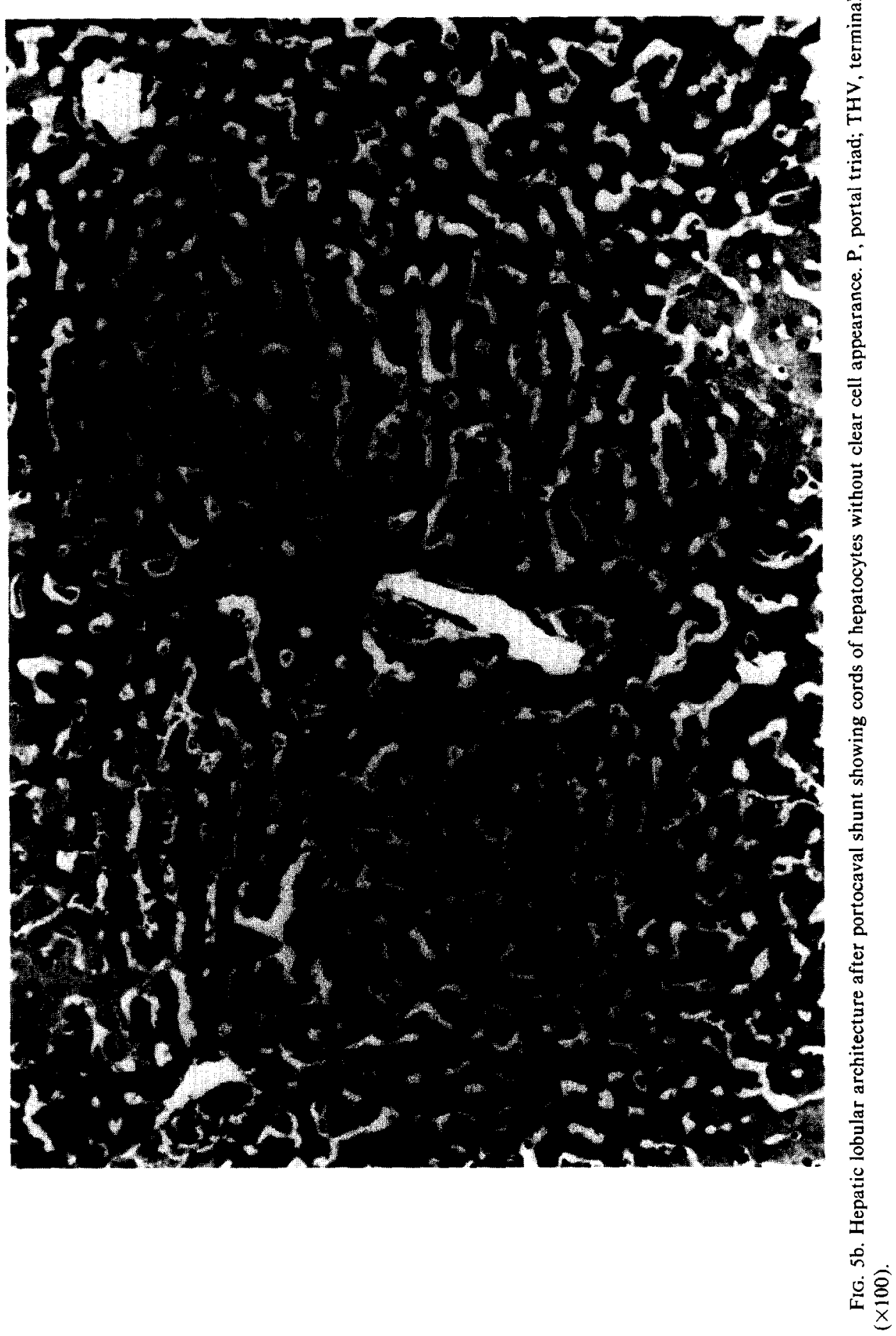




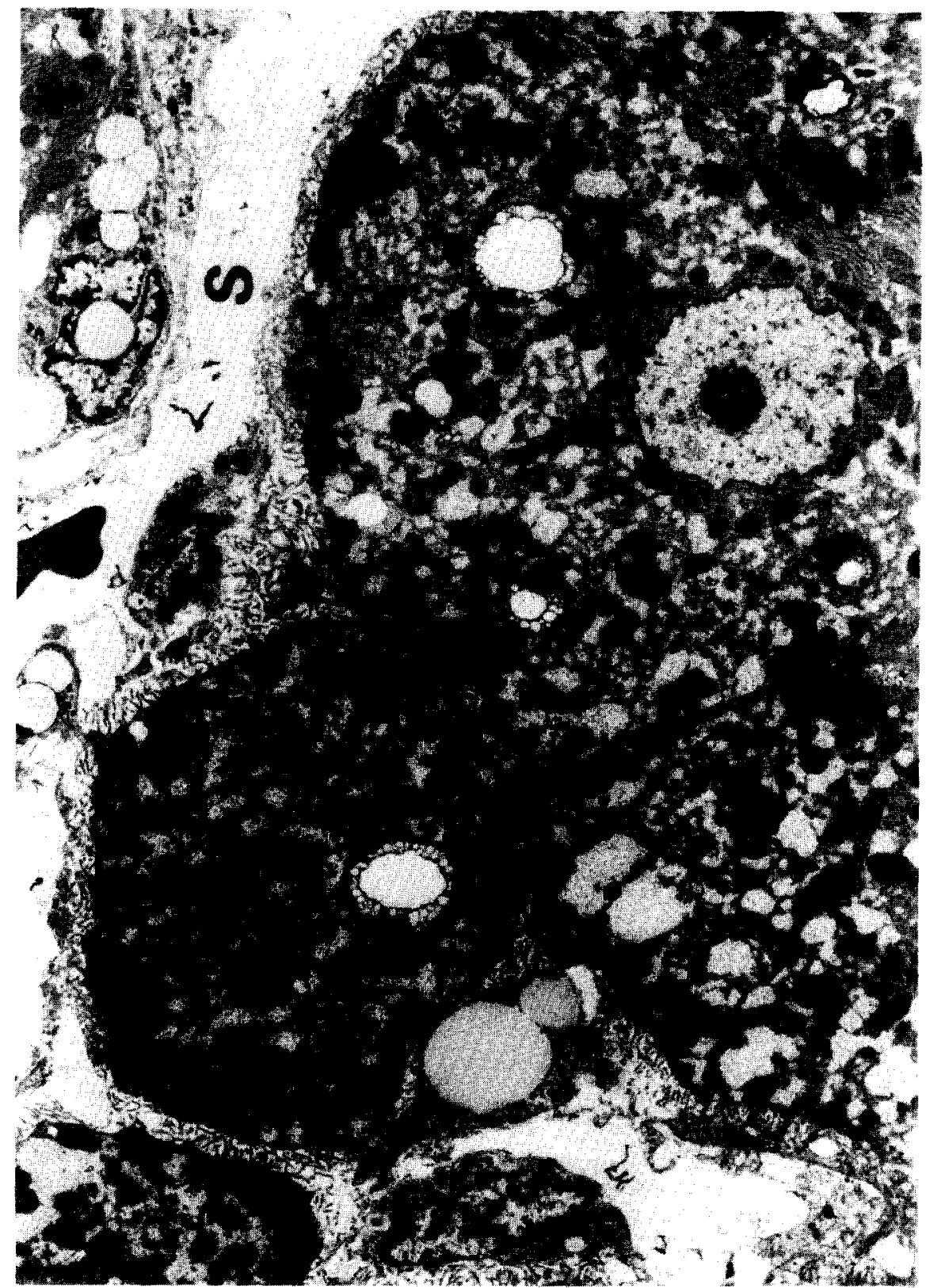




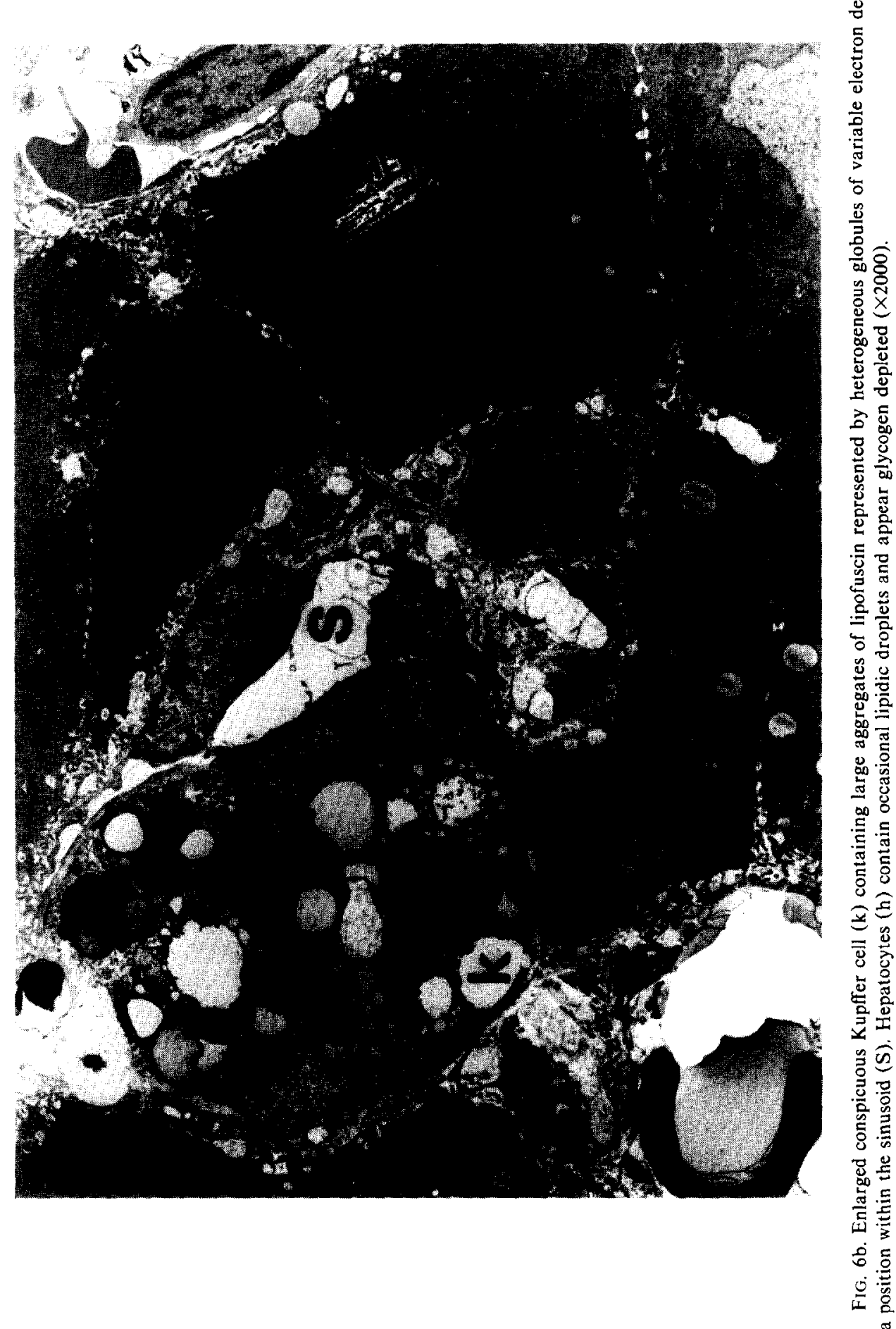

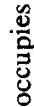

: 
vesiculation and fragmentation. Lysosomes appeared slightly increased in number. Spaces of Disse were more dilated and contained moderately increased amounts of collagen. Fat-storing cells and endothelial cells seemed unaffected. Kupffer cells appeared larger and contained abundant phagolysosomes filled with osmophilic debris (Fig. 6b).

\section{DISCUSSION}

The reticuloendothelial system has been shown to be a major host defense mechanism. The phagocytic and metabolic activity of fixed macrophages appears to be regulated by many factors including organ blood flow [3] and metabolic or functional status of the RE cells $[19,22]$. In addition, reactive serum factors or opsonins have been demonstrated to be important for in vivo and in vitro Kupffer cell phagocytosis of both microorganisms and inert particulate matter $[22,23,26,27]$.

The majority of intravascular phagocytic activity occurs in the liver and has been attributed to the large resident population of Kupffer cells and to its extensive blood flow $[4,24]$. Several investigators have demonstrated that complete diversion of portal blood flow into the systemic circulation adversely affects hepatocellular structure and function $[30,31]$. These alterations have been correlated not so much with changes in total liver blood flow per se as with hepatic deprivation of endogenous "hepatotrophic" factors normally contained in portal blood $[29,30]$.

Hepatocyte atrophy was pronounced following PCS and there was ultrastructural evidence of deglycogenation and decreases in rough endoplasmic reticulum (RER). Starzl et al. demonstrated similar histological findings and in addition, using morphometric analysis, showed a 50 to $70 \%$ reduction in the area of RER per volume of cytoplasm and a reduction in the number of membrane-bound ribosomes [30]. Since the synthesis of albumin in liver cells is related to ribosomes and RER [13], the fall in plasma protein concentration observed in this study was thought to reflect impaired production. In contrast, there are few morphological data regarding the effects of portal diversion on Kupffer cells of the liver and much of the information pertaining to this population of cells is incomplete.

While hepatic blood flow has been related to $\mathrm{RE}$ activity $[4,25]$, there appears to be an inverse correlation between the rate of blood flow and the efficiency of colloid extraction by the liver $[2,24]$. Saba suggested that factors which tended to decrease transit time through the liver would decrease contact time between particles and macrophages [24]. His findings supported earlier observations that the extraction ratio and perfusate flow rate were inversely related [2].

These data suggest that canine Kupffer cells may be more resistant to portoprivation than hepatic parenchymal cells. The liver's response to increasing hepatocyte "dropout" is "low-grade" proliferation demonstrable by autoradiography [30]. However, this compensatory hyperplasia is not proportional to the rate of cell death and may result in reduced liver mass. The demonstration by light microscopy in this study that Kupffer cells enlarge and become more prominent following PCS confirms an earlier, similar observation by Starzl et al. [31]. There is now increasing evidence that macrophages can significantly increase functional activity following phagocytosis by undergoing intracellular modifications [22]. It is also clear that reexposure of macrophages presensitized to a specific antigen with the same stimulus can result in rapid multiplication. MacKaness demonstrated markedly increased numbers of mitoses and increased $\left[{ }^{3} \mathrm{H}\right]$ thymidine labeling of mouse peritoneal macrophages challenged with a second antigen to which the animal has been previously sensitized [20]. It is unclear, however, whether this response results from hepatocyte atrophy or from macrophage proliferation as suggested by others [22]. Portoprivation may well be cell selective, affecting 
hepatic parenchymal cells to a greater extent than reticuloendothelial cells.

The clinical evidence of altered or compromised hepatic RE function in patients with severe chronic liver disease (cirrhosis) has been inferred from studies showing reduced intravascular clearance of particulate material $[4,10]$ and an increased prevalence of systemic endotoxemia $[15,18]$ in these patients.

Cooksley et al. studied RE function in patients with alcoholic cirrhosis and observed that phagocytic capacity (REPC) in patients with decreased RE (sinusoidal) perfusion was significantly less than that in patients with normal RE perfusion [10]. Furthermore, he demonstrated a strong correlation between phagocytic activity and perfusion in all patients with liver disease, suggesting that REPC is a perfusion-dependent phenomenon. In contrast, experimental and clinical studies have demonstrated acute alcohol-induced depression of RE function without associated changes in hepatic blood flow $[1,17]$. The factor(s) responsible for depressed REPC after alcohol administration are unclear. Intravenously administered ethyl alcohol does not acutely alter regional hepatic blood flow in man. Liu speculated that the decrease in REPC observed in his patients might have been caused by depletion of serum opsonins [17]. Alternatively, alcohol may act on macrophages at the cellular level to cause changes in phagocytic capacity. Only Jeunet et al., using an isolated perfused liver model, have demonstrated an association between RE blockade and decreased Kupffer cell function [16]; other investigators have attributed this phenomenon to depletion of opsonins $[21,23$, 26, 27].

Cirrhosis is a chronic disease which with progressive enlargement of portosystemic collaterals [28] ultimately results in reduced effective hepatic perfusion [8]. Patients with advanced disease, especially those with ascites, often exhibit clinical and radiographic evidence of portosystemic shunting and markedly decreased sinusoidal perfusion [4,
10]. The impaired hepatic clearance of portal endotoxin and bacteria which have been demonstrated experimentally and in patients with cirrhosis $[14,15,32]$ could be due to either to Kupffer cell failure or "spillover" secondary to decreased RE perfusion and intrahepatic portosystemic shunting of blood [7].

Our study demonstrates that despite portocaval shunting and its attendant changes in hepatocellular structure and function, Kupffer cell phagocytosis and metabolism of ${ }^{131}$ I-labeled test lipid emulsion in the dog remains normal. The enhanced tissue uptake on a per gram basis by the liver can be explained by increased functional activity of existing Kupffer cells, proliferation of Kupffer cells, or both. Kupffer cells appear to be more resistant than hepatic parenchymal cells to portoprivation.

Opsonic activity measured by carboxy-latex particle agglutination or determination of the $\alpha-2$ globulin fraction of serum protein does not appear to correlate with RE phagocytic capacity for RES lipid emulsion in the dog. A lack of specificity and/or sensitivity of available techniques to measure opsonic activity may account for these findings.

\section{REFERENCES}

I. Ali, M. V., and Nolan, J. P. Alcohol induced depression of recticuloendothelial function in the rat. $J$. Lab. Clin. Med. 70: 295, 1967.

2. Asiddao, C. B., Filkins, J. P., and Smith, J. J. Metabolic and surface factors governing phagocytosis in the perfused rat's liver after partial hepatectomy. Amer. Med. Assoc. Arch. Pathol. 53: 197, 1952.

3. Benacerraf, B., Biozzi, G., Cuendet, A., and Halpern, B. N. Influence of portal blood flow and of partial hepatectomy on the granulopectic activity of the reticuloendothelial system. $J$. Physiol. 128: $1,1955$.

4. Biozzi, G., Benacerraf, B., Halpern, B. N., Stiffel, L., and Hillemand, B. Exploration of the phagocytic function of the reticuloendothelial system with heat denatured human serum albumin labeled with $I^{131}$ and application to the measurement of liver blood flow in normal man and in some pathologic conditions. J. Lab. Clin. Med. 51: 230, 1959.

5. Biozzi, G., and Stiffel, C. The physiology of the reticuloendothelial cells of the liver and spleen, In H. Popper and F. Schaffner (Eds.), Progress in 
Liver Diseases. New York: Grune \& Stratton, 1965. Pp. 166-191.

6. Blumenstock, F., Sabar, T. M., Weber, P., and Cho, E. Purification and biochemical characterization of a macrophage stimulating alpha-2-globulin opsinic protein. J. Reticuloendothel. Soc. 19: 157, 1976.

7. Bradfield, J. W. Control of spillover: The Importance of Kupffer cell function in clinical medicine. Lancet 2: 883, 1974.

8. Bradley, S. E., Inglefinger, F. J., and Bradley, G. P. Hepatic circulation in cirrhosis of the liver. Circulation 5: 419, 1952.

9. Check, I. J., Wolfmon, H. C., Colet, T. B., and Hunter, R. L. Agglutination assay for human opsonic factor using gelatin-coated latex particles. $J$. Reticuloendothel. Soc. 25: 351, 1979.

10. Cooksley, W. G. E., Powell, L. W., and Halliday, J. W. Reticuloendothelial phagocytic function in human liver disease and its relation to hemolysis. Brit. J. Haematol. 25: 147, 1973.

11. Diluzio, N. R., and Riggi, S. J. The development of a lipid emulsion for the measurement of reticuloendothelial function. J. Recticuloendothel. Soc. 1: $136,1964$.

12. Dobson, E. L., and Jones, H. B. The behavior of intravenously injected particulate material. Acta. Med. Scand. 273 (Suppl.): 1, 1952.

13. Feldman, G., Penaud-Laurencin, J., Crassons, J., and Benhamon, J. P. Albumin synthesis by human liver cells: Its morphological demonstration. Gastroenterology 60: 1036, 1972.

14. Grun, M., and Liehr, $\mathbf{H}$. Biological significance of altered von Kupffer cell function in experimental liver disease, In E. Wisse and D. L. Knook (Eds.), Kuppfer Cells and Other Liver Sinusoidal Cells. Amsterdam: Elsevier/North-Holland, 1977. P. 437.

15. Jacob, A. I., Goldberg, P. K., Bloom., N., Degenschein, G., and Kozina, P. J. Endotoxin and bacterial in portal blood. Gastroenterology 72: 1268 , 1977.

16. Jeunet, F. S., Cain, W. C., and Good, R. A. Recognition phenomena studied by a liver perfusion system, In R. T. Smith and R. A. Good (Eds.), Cellular Recognition. New York: Appleton-Century-Crofts, 1969. Pp. 295-304.

17. Liu, Y. K. Phagocytic capacity of reticuloendothelial system in alcoholics. J. Reticuloendothel. Soc. 25: 605, 1979.

18. Liehr, H., and Grun, M. Clinical aspects of Kupffer cell failure in liver disease, In E. Wisse and D. L. Knook (Eds.), Kupffer Cells and Other Liver
Sinusoidal Cells. Amsterdam: Elsevier/NorthHolland, 1977. P. 379.

19. Loegering, D. J., and Schneikdraut, M. J. Effect of endotoxin on alpha-2 SB-opsonic protein activity and reticuloendothelial system phagocytic function. J. Reticuloendothel. Soc. 26: 197, 1979.

20. Mackaness, G. B. Cellular resistance to infection. J. Exp. Med. 116: 381, 1962.

21. Murray, I. M. The mechanism of blockade of the reticuloendothelial system. J. Exp. Med. 117: 139, 1963.

22. Rowley, D. Phagocytosis and immunity. Experientia 22: $1,1966$.

23. Saba, T. M., and DiLuzio, N. R. Kupfer cell phagocytosis and metabolism of a variety of particles as a function of opsonization. $J$. Reticuloendothel. Soc. 2: 437, 1966.

24. Saba, T. M. Liver blood flow and intravascular colloid clearance alterations following partial hepatectomy. J. Reticuloendothel. Soc. 7: 406, 1970.

25. Saba, T. M. Physiology and physiopathology of the reticuloendothelial system. Arch. Int. Med. 126: $1031,1970$.

26. Saba, T. M., Filkins, J. P., and Diluzio, N. R. Properties of the "Opsonic System" regulating in vitro hepatic phagocytosis. J. Reticuloendothel. Soc. 3: 398, 1966.

27. Saba, T. M., and DiLuzio, N. R. Reticuloendothelial blockade and recovery as a function of opsonic activity. Amer. J. Physiol. 216: 197, 1969.

28. Sherlock, S. Portal venous system and portal hypertension, In S. Sherlock (Ed.), Diseases of the Liver and Biliary Tract. Oxford: Blackwell, 1975. Pp. 150-216.

29. Starzl, T. E., Porter, K. A., Kashiwagi, N., and Putnam, C. W. Portal hepatotrophic factors, diabetes mellitus, and acute liver atrophy, hypertrophy, and regeneration. Surg. Gynecol. Obstet. 141: 843, 1975.

30. Starzl, T. E., Porter, K. A., Watanabe, K., and Putnam, C. W. Effects of insulin/glucagon infusions on liver morphology and cell division after complete portacaval shunt in dogs. Lancet 2: 821 , 1976.

31. Starzl, T. E., Lee, I. Y., Porter, K. A., and Putnam, C. $W$. The influence of portal blood upon lipid metabolism in normal and diabetic dogs. Surg. $G y$ necol. Obstet. 140: 381, 1975.

32. Whipple, R. L., and Harris, J. F. B. coli septicemia in Laennec's cirrhosis of the liver. Ann. Int. Med. 33: $462,1950$. 